\title{
PROFILE
}

\section{Active Conflict or Passive Coherence? The Political Economy of Climate Change in China}

\author{
Alex Y. Lo* \\ School of Politics and International Relations, Australian National University, \\ Australia
}

\begin{abstract}
Mounting international pressure on China to accept binding targets for reducing carbon emissions appears to have put the Chinese public firmly behind the state's defence of national autonomy in formulating responses to climate change. This widely shared support for autonomy may then indicate a passive form of political coherence, where official policies and public preferences are not in conflict. This profile examines some evidence for this hypothesis and calls for further exploring the role of global environmental controversies in shaping domestic politics in China, a political context devoid of legal oppositional politics.
\end{abstract}

Keywords: China, climate change, civil society

Human-induced climate change has been a trigger of domestic conflict in many parts of the world. In politically diverse societies, the climate change controversy has motivated groups at opposite poles of the political spectrum, prompting prolonged periods of contention between environmental activists and climate change sceptics. But what about countries without legal oppositional politics, such as China?

China ratified the United Nations Framework Convention on Climate Change and the Kyoto Protocol in 1992 and 2002, respectively. As a non-Annex I developing country it has not been subject to emission limits. Although it does not run short of

\footnotetext{
*Email: alex.lo@anu.edu.au
} 
aggressive mitigation efforts, there is strong reluctance to curb the skyrocketing emission levels by adhering to mandatory emission limits. Substantial climate commitment from China is contingent upon fulfillment of its own economic and social goals. This is accepted not only by the government and business leaders, but also the general public and many NGOs. These actors converge in their views about the relative priority of responsibility for climate change and for the majority's material wellbeing. Moreover, Chinese citizens and civil society do not, or cannot, confront the state. The issue of climate change, then, does not involve a great deal of conflict; Chinese nationalism, moreover, may keep it that way for the foreseeable future. Many Chinese strongly disapprove of Western criticisms concerning their country's political traditions. Following the Copenhagen conference and in view of China’s rapidly growing energy consumption, the government is confronted with mounting international pressure demanding further concessions. The dynamics of global climate politics, however, may effectively create a political arena where the Chinese public remains firmly behind the state's defence of national autonomy in formulating responses to climate change. This widely shared support for autonomy may then indicate a passive form of political coherence, where official policies and public preferences are not in conflict. This profile examines some evidence for this hypothesis and calls for further exploring the role of global environmental controversies in shaping domestic politics in China. 


\section{Policy Scope}

The latest Chinese position on climate change is outlined in three official documents. The "National Climate Change Programme" launched by the Chinese government in 2007 and "China's Policies and Actions for Addressing Climate Change” released in 2008 are essentially energy economy blueprints. The overarching guidelines listed involve a range of policy objectives, with protecting economic growth highlighted as the core. Continual emissions growth is literally recognised as unavoidable. The policy objective is to minimise emissions for the state of economic prosperity desired. There is a general emphasis on technological transition in industrial and agricultural production processes through promoting energy efficiency and optimizing the energy mix. Technical expertise plays a key role.

Chinese climate policies are couched in terms of efficient natural resource consumption. China's Policies and Actions for Addressing Climate Change - The Progress Report (2009) details the massive efforts to reduce the economy's energy intensity. The action plan is fraught with command-and-control measures. Institutional arrangements being put in place remain top-down and lack opportunities for political engagement by the public. The only social initiative involves publicity campaigns, which serve educational purposes rather than creating social capital essential to 
long-term success. The main themes of public participation are merely information dissemination and consumption reduction.

Formal responsibility for climate change policy lies with the National Development and Reform Commission (NDRC), one of the most powerful government agencies in China. The NDRC is charged with developing economic strategies primarily to maximise economic growth. It oversees the Department of Climate Change and chairs the National Coordination Committee on Climate Change. The 2008 document cited above affirms the NDRC's lead in formulating climate policies and coordinating international negotiations. In contrast, the national environmental agency, which was converted into the Ministry of Environmental Protection in early 2009, plays only a marginal role (Richerzhagen and Scholz 2008). None of the three official documents makes reference to the Ministry or its predecessor. This difference in official recognition indicates a steep power asymmetry between the economic and the environmental agencies.

China's approach to climate change is generally pragmatic. Actions for the climate are considered worthwhile because of the potential threats to national stability, through energy security and domestic social and health impacts, rather than global climate change commitments. Climate policy is viewed not as a cross-sectoral environmental issue, but largely an economic one (Richerzhagen and Scholz 2008). 


\section{Civil Society}

Historically, Chinese environmental NGOs were active only at local or regional level. Since the 1980s the centrally planned public domains, including social services, have been gradually returned to society. Many NGOs have benefited from this limited decentralisation and emerged as local service providers. There is at present no Chinese NGO solely dedicated to climate mitigation and adaptation, but an NGO network, the Chinese Civil Climate Change Action Network, was set up in 2007 for exchange of information and experience and joint actions.

NGOs are seen by the Chinese government as a potential social force threatening the leadership. Demanding entry barriers are imposed on new, bottom-up NGOs, and the existing ones are under strict administrative control. Conformity with official policies is a necessary condition for their activities to be recognised by the government. Only government-organised NGOs (GONGOs), and those having established alliances with government people who share their views, have some political access.

Non-governmental actors by and large do not influence climate policy-making (Liu 2009). One reason is that many NGOs lack the expertise required to deal with highly complex climate change issues, expertise being the only acceptable form of limited non-governmental participation in policy formulation. Most such critical 
feedback signals come from domestic research institutions, many of which are associated with governmental actors. Beyond such expressly non-political influence based on scientific and technical expertise, the nature of centralised decision-making in China simply does not leave much scope for independent action on key national issues (Richerzhagen and Scholz 2008). Where national economic stability and global leadership are at stake, it is even harder for civil society to influence the formal policy community.

Activities of non-governmental climate actors then have little critical intent. Not only GONGOs but also grassroots NGOs avoid challenging the central policy. Pressuring tactics are rare and radical climate campaigners are not active. Schroeder (2008) found that NGOs in China rely mainly on media and information campaigns to influence policy decisions on climate change. This may be a passive response to their lack of influence on the central decision-making processes.

NGOs operate within a scope acceptable to the government. Instead of criticising the central state, they target local issues that have an immediate impact on local living conditions. There have been massive efforts at encouraging household mitigative and adaptive transition and providing the technical and financial supports required. There has been some success in helping rural inhabitants improve combustion efficiency and adapt to water shortage. Urban initiatives involve little more than publicity campaigns 
framed in the context of demand-side energy saving. The largest is the " $20 \%$ Energy Saving Citizen Actions” campaign launched in 2007, a joint action network involving more than 40 local NGOs and 17 Chinese provinces. This energy efficiency programme aims to enhance public awareness and encourage energy saving in daily life, is recognised by the central government and supports its energy intensity target.

Chinese environmental NGOs remain non-confrontational in the international arena as well. Formal engagement in international climate networks is in an initial stage. Their first participation in the international climate conference in Bali in December 2007 led to a joint declaration with transnational NGOs, which was described as conservative and conforming to the Chinese government's position (Schroeder 2008). Knowledge diffusion is the primary purpose of their involvement. Chinese NGOs hesitate to adopt the shaming strategies of western NGOs (Schroeder 2008). The protest culture prevalent among international climate activists is not on their agenda.

A historical reason for their belated involvement is organisational localisation. Most Chinese NGOs lack the international experience, expertise and financial support required to go global. Their dependence on the bureaucratic system has imposed further restrictions. Civil society thus has limited capacity to coordinate independent political action on climate change. As suggested by an active member of a Chinese NGO, feasible international actions are those that seek to affirm developed countries' larger 
share of responsibility and help the Chinese government demand more from them. Chinese civil society organisations explicitly align their official positions with these national norms (Liu 2009).

Citizens give much more priority to economic growth than environmental protection. Environmental values in contemporary China are far more dependent on personal utility than nature’s intrinsic value (Harris 2004). Many Chinese individuals accept environmental degradation if it is an unavoidable by-product of the struggle for prosperity. According to a national survey launched by the Chinese Academy of Social Sciences (CASS) in December 2007, the most serious problems in China were healthcare, employment and income inequality.

Individual citizens do not view climate change as the most pressing environmental problem. In the CASS survey, the greenhouse effect and climate change were ranked fourth in terms of general awareness and perceived seriousness. The enhanced greenhouse effect was perceived by Chinese students to be of moderate urgency (Wong 2003). Among ten global environmental problems, it was ranked sixth while desertification and deforestation were listed at the top. Fewer than $6 \%$ of respondents thought that the general public should be responsible for protecting the environment (Wong 2003).

Another national survey was administered by the Horizon Research Consultancy 
Group in 2009 and focused specifically on Chinese people's attitudes toward climate change. Climate change was again ranked fourth in terms of seriousness among ten environmental problems, far behind air quality, waste and sewage management problems. About $74 \%$ of the respondents attributed efforts at tackling the climate change problem to the government, and only 6.5\% to individual citizens (exclusive choices). Likewise, $72.3 \%$ ascribed climate responsibility to the government, and only $6 \%$ to citizens.

Compared with other countries, the level of concern expressed by the Chinese public is in general modest. According to a report summarizing several global surveys (Leiserowitz 2007), China has a greater proportion of citizens who have heard of global warming than do other developing countries. However, few Chinese individuals rated global warming as a "very serious" problem and few strongly believed that it would pose a threat to them - fewer than in many other developing countries. Along with Americans, people in China were those least likely to worry about climate change.

These survey findings suggest that ordinary Chinese citizens are not highly motivated to play an active part in the climate movement. One possible reason is that climate change does not immediately affect their material well-being, which happens to be a dominant form of public value in China today. This low sense of individual responsibility may also be a consequence of the prolonged dominance of centralised 
governance where the government is expected to take full responsibility for the environment. Passive citizens, especially those focused on personal economic gain, do not seek to participate in making climate policies.

\section{Implications}

The Chinese discourse on climate change is highly pragmatic and dominated by governmental actors. It is characterised by a two-level power asymmetry prevalent in developing countries: economic vs. environmental agencies, and state vs. civil society. Oppositional social forces are perhaps even less influential in China than in other major developing countries.

The observation, however, is not generalisable. On some issues environmental NGOs have challenged the state. Regional air and water pollution problems in China are being tackled at an economic cost. Non-governmental actors are active in the protection of rural ecosystems and occasional protest against key infrastructural projects, such as the building of Three Gorges Dam. Over the years they have gained more access to politics and economic resources for dealing with those environmental issues that are closely linked to the livelihood of the current and next generations.

As far as the global environment is concerned the power relationship appears to be more asymmetrical. Climate change is perceived by state leaders as an exceptionally 
important problem that could pose a serious threat to national stability and its global leadership. As a tradition of Chinese politics, then, more state control is favoured. Civil society is politically not motivated and ill-equipped to cope with such a complex issue. Domestic political and civil forces are presently unlikely to be key drivers of climate policy change in China.

In countries like Australia, social actors and electorates are more active and powerful in the domestic politics of global climate change. Conflicts are not uncommon between uninterested governments and the concerned public, oil industry and NGOs, and the scientific community and climate sceptics. China diverges from its developed counterparts in the sense that global climate change (contrary to the leadership’s fears!) has not created major internal conflict that could lead to domestic political instability. It is worth exploring whether or not the reverse is true: the mounting international pressures might have fostered internal solidarity against the western "intervention" in the form of binding environmental agreements that might compromise the economic fortunes of 1.3 billion people. Concerns about "carbon colonisation" may encourage nationalistic dispositions. There is an unspoken consensus between the state and civil society on key principles, such as differential responsibility, the overriding importance of economic interest, and non-political forms of public participation. Civil society fails to confront the state, and the official agenda has little conflict with current public 
preferences. Chinese climate change discourse appears to be characterised by a passive form of political coherence.

\section{References:}

Harris, P.G., 2004. 'Getting rich is glorious': Environmental values in the People's Republic of China. Environmental Values, 13, 145-165.

Leiserowitz, A., 2007. International public opinion, perception, and understanding of global climate change. Human Development Report Office Occasional Paper, 2007/31. United Nations Environment Programme.

Liu, H., 2009. The impact of climate change on China In: D. Yang, ed. The China environment yearbook: Crises and opportunities Leiden: Brill

Lo, C.W.H. and Leung, S.W., 2000. Environmental agency and public opinion in Guangzhou: The limits of a popular approach to environmental governance. The China Quarterly, 163, 677-704.

Richerzhagen, C. and Scholz, I., 2008. China's capacities for mitigating climate change. World Development, 36 (2), 308-324.

Schroeder, M., 2008. The construction of China's climate politics: Transnational NGOs and the spiral model of international relations. Cambridge Review of International Affairs, 21 (4), 505-525.

Wong, K.-K., 2003. The environmental awareness of university students in Beijing, China. Journal of Contemporary China, 12, 519-536. 